\title{
Research on connotation of low-carbon urban construction based on the demand level theory
}

\author{
Li Xudong, Fan Denglong \\ Chongqing University of Science and Technology, Chongqing, 401331
}

Keywords: Demand level; low - carbon city; Connotation

\begin{abstract}
Based on the cognition and demand of low - carbon city construction, this paper analyzes the satisfaction of low - carbon city construction to different needs of mankind, studies the connotation of low - carbon city construction based on demand level, and puts forward the corresponding Advice and suggestions, with a certain degree of innovation.
\end{abstract}

\section{Introduction}

At present, the problems of environmental pollution, water shortage and greenhouse effect brought by urbanization have seriously affected the survival and development of human beings. The problem of urban residents living in "heat island effect" has become increasingly prominent. The development of low-carbon economy, the construction of low-carbon city, to promote economic, social, cultural and other common progress, to achieve comprehensive and coordinated economic and social sustainable development, urban construction to provide a new development path. The development of low-carbon economy, the construction of low-carbon city is not only a change in economic development model, but also a change of thought, behavior change. How to meet the human physiological and psychological needs in the existing resources and environmental constraints, to achieve the needs of people from outside to gradually meet the satisfaction of the internal transformation, the need to study the human psychological and behavioral laws, as well as to meet the individual needs Internal motivation to start, from the perspective of the needs of residents, the construction of low-carbon city.

\section{Demand Theory and Low - Carbon City Construction}

American humanistic psychologist Maslow put forward the "demand-level" theory, the need to divide the physiological needs, security needs, social needs, respect for the needs and self-realization of five levels, and that only low-level needs to meet, A higher level of demand will be shown.

Physiological needs are the direct relationship with the survival of organisms, including clothing, food, housing, transportation and other aspects of the requirements of human survival is the basic requirements, but also to promote people's actions the most powerful driving force.

The whole organism is a mechanism that emphasizes safety. When people 's physiology needs to be satisfied, hope that labor safety, occupational safety, life stability, avoid disaster and so on, in order to reduce the uncertainty in life.

Social needs are the needs of love and attribution, refers to the individual desire for family, friends, colleagues, the relationship between harmony, mutual care and understanding, friendship, trust, warmth, love needs.

Respect needs to include self-respect, self-evaluation and respect for others. That is, want to have their own strength, competent, confident, can be independent. And hope that they have prestige, status, by others respect and highly appraised.

Self-realization is the highest level of need, is a need to create, that can best play their own potential, to achieve personal ideals, aspirations, to complete their own needs with the power of the needs of the desired people. 
In Maslow's view, people are hidden in these five different levels of needs, but in different periods of the various needs of the urgency are different. Physical, security, social needs are low-level needs, these need to meet through external conditions, and personal respect and self-realization of the need is endless, are high-level needs, must be internal factors can really be satisfied, at all levels Need to influence each other, interdependence. The demand hierarchy of a majority of the country is closely related to the economic level, technological level, educational level and educational level of the country.

Low-carbon city is based on urban space as the carrier, the development of low-carbon economy, innovation and low-carbon technology, change the concept of consumption, to achieve low-carbon lifestyle, the establishment of a healthy and sustainable energy ecosystem. Most of the current research and views on low-carbon cities, most of the low-carbon city that is a new concept of development, through the realization of energy consumption reduction and low carbon dioxide emissions to achieve, more from the macroeconomic point of view or In the specific operational, applicability or other aspects of the analysis. However, the effect of urban construction, in a certain period of time the total urban economy is composed of microeconomic volume, and these micro-economic volume is completed by the city's main body of behavior, urban construction of the main constraints or affect the city The construction of the situation, the main body of the behavior of these urban construction is the construction of urban actors - urban residents. It can be seen that low-carbon cities are based on people's current needs of life and the environment. Therefore, in the exploration and practice of low-carbon urban construction, we should first study the psychological and behavioral laws and human needs To start.

\section{The "Demand Level" Theory under the Low Carbon City Construction}

Corresponding to the five levels of Maslow's demand, from the study of people's psychological and behavioral needs of the start, the construction of low-carbon city is the inevitable development of human society, but also the needs of people from outside to gradually meet the internal satisfaction of the transformation, It is not only the need of harmonious development of mankind, society and nature, but also the important reason and powerful driving force for the construction of low-carbon city. Corresponding to Maslow's "demand level" theory, low-carbon city can better meet the current requirements of people from low to high five levels of demand.

Scientific and low-carbon city planning, improve the low-carbon city policy support system, urban industrial structure, energy consumption structure of the rational allocation and use; energy saving, green, environmentally friendly low-carbon city construction and transportation planning; from production, processing to packaging, Consumption of low-carbon food system; good air quality, water quality, suitable living conditions and so on. Low-carbon city construction is for people's food and shelter and other basic physiological needs, providing a better living, living, working conditions and the environment.

Low-carbon city construction is to better meet people's sense of security for human survival and development to provide better protection. The level of carbon emissions is an important indicator of low-carbon urban construction. In the "low-carbon city" characterized by "low-emission, energy-efficient and high-efficiency", everyone in the haze society, benign and sustainable development Energy and ecological system can better reduce environmental pollution, reduce or avoid floods, earthquakes, fires and other disasters; through the adjustment of industrial structure and development model of low-carbon production, will promote a new round of economic growth, good Economic environment, can provide people with more employment opportunities, improve living standards; at the same time will further improve the pension, health insurance and other social security mechanisms and public security, medical and other professional institutions.

The purpose of low-carbon city construction is to establish a resource-saving, environment-friendly, benign and sustainable energy ecosystem. All kinds of parks, squares and other living environment optimization, supporting facilities are available for social interaction to provide a more favorable public space; the proportion of urban energy-saving cars, urban public transport coverage for urban residents travel and exchanges, to provide more Public transport types, 
increased coverage, convenience and accessibility. Based on the social needs of the "environment-friendly" low-carbon city, is the economic development, social progress and environmental protection three coordinated development model, more able to live in society to provide more social and social facilities.

Health, saving, low-carbon way of life and consumption is a significant feature of low-carbon city construction, a long time in the city's construction and development, people are relatively more to pursue the greatest effect of things, leading to ecological harmony imbalance, interpersonal The relationship deteriorates. Pay attention to ecological balance, interpersonal harmony of low-carbon city construction, let people re-examine the value orientation, pay more attention to the value of the behavior itself to achieve social justice, justice, integrity and credibility. The fair distribution of various resources so that residents enjoy equal education, social security and other rights. In urban construction design, road traffic, etc., pay more attention to the care of vulnerable groups, more humane. From the respect of demand, low-carbon city construction can make people who really feel the importance and respect, truly reflect the social harmony.

Low-carbon urban construction enables people to establish correct ecological values. Environmental culture, so that the human resistance to live in the city has a more beautiful natural landscape and cultural landscape; ecological culture can achieve the harmonious development of man and nature, and guide the sustainable development of society; not to reduce the content of life, sacrifice quality of life, reduce Life desire of the new conservationism, but also allow people to live out the essence of life; social individual moral qualities and moral quality to further enhance the social morality and social habits more well. Low-carbon eco-city construction, can make the individual not only to achieve economic interests, but political, cultural, social, ecological, economic interests at the same time to achieve, so that people take a rational attitude to life, pragmatic attitude to face life, From which to feel the value of self, to achieve its ideals.

\section{The "Demand Level" of Low - Carbon City Construction Countermeasures}

Construction of low - carbon cities related to the production, life, ecology, humanities, social aspects of the building. The development of low-carbon economy, the urgent need to "low carbon" to adapt to the emergence of the mainstream concept, so that low-carbon within the social production and residential life, which gradually change the economic and social production behavior and life behavior. Therefore, it is necessary to effectively mobilize and play the enthusiasm of the individual in the micro-subject through various channels, and analyze the countermeasures of low-carbon city construction from the perspective of the "demand level" of the low-carbon city construction behavior subject.

To build a low-carbon city, we must first establish the ecological values. To guide people "value rationality", re-examine the value orientation. To actively guide people to pay attention to the value of the act itself can be abandoned, too much attention to the value of tools, the pursuit of temporary happiness but at the expense of long-term happiness at the expense of behavior, reshaping human values rational and rational behavior, create low-carbon eco- Pay attention to ecological balance, coordination of harmony between man and nature.

In the national advantage of the diamond system, demand conditions played an important role. Consumers of the product, service requirements or critical level is very strong, the corresponding will stimulate the competitive advantage of the enterprise. Such as Japanese consumers in the car consumption is critical of the world's famous, Europe's strict environmental requirements also make many European companies car environmental performance, energy-saving performance of the world-class. So to make low-carbon city has a lasting competitiveness, from the consumer's point of view, is to establish a low-carbon consumer awareness, cultivate low-carbon consumer demand, from the consumer demand to increase the enterprise products Low-carbon technology pressure, so that consumer demand to force the community, government, business change and innovation environment.

We should actively guide residents to change the waste of energy, waste of resources consumption patterns, and fully tap the low potential of low consumption of living space. To 
promote the development of renewable energy and building; to implement urban forest engineering, to reduce the city, to promote the development of new energy sources, to reduce the coal and electricity energy pollution; to encourage residents to implement building energy efficiency, Heat island effect; guide residents to choose low-carbon life, the implementation of green consumption and green lifestyle.

Ecological society is the rational choice of post-industrial civilization, and create an ecological civilization atmosphere can have a lasting influence on the construction of low-carbon city, and have a strong restriction on the life of urban residents. Through the cultivation of ecological awareness of residents, to encourage participation in low-carbon activities, the formation of low-carbon consumption habits, to promote universal conscious action and extensive participation in the formation of low-carbon atmosphere of the city.

\section{Conclusion}

Construction of low-carbon city is not only the economic development model of change, it is a change of thought, behavior change. Based on the theory of Maslow's demand hierarchy, this paper constructs the evaluation index system of low - carbon cities based on the "demand level" through the research on the demand hierarchy of urban residents' psychological and behavioral laws. On this basis, the corresponding countermeasures and suggestions are put forward, Carbon city construction of the role of the main body, with a certain innovation and pragmatism, but also for the construction of low-carbon city to provide a new perspective.

\section{Acknowledgements}

Fund Project: 2016 Chongqing Municipal Education Commission Science and Technology Research Project: Based on the needs of residents of the main needs of low-carbon city construction countermeasures Project No.: KJ1603110

\section{References}

[1] Bao Jianqiang, Miao Yang, Chen Feng. Low-carbon economy: the new transformation of human economic development [J]. China Industrial Economy, 2008 (153-160).

[2] Xia Kun Fort. Development of low-carbon economy to achieve sustainable urban development [J]. Environmental Protection, 2008, (33-35).

[3] Cao Li. Maslow demand hierarchy theory in the western economics teaching research [J]. Shopping modernization, 2010, (91)

[4] Zhu Peng, Yao Yifeng, Zhang Peigang.Study on the Evaluation Index of "Livable City" Based on Human "Demand Level" Theory [J]. Henan Science, 2006, (136) 